\title{
Metamaterial Based Circular Disc Patch Antenna Miniaturization
}

\author{
*Varindra Kumar', Yutian $\mathbf{W u}^{2}$
}

\author{
${ }^{1}$ Dept. of Engineering, University of Cambridge, Trumpington Street, CB2 1PZ Cambridge, UK \\ ${ }^{2}$ Cavendish Laboratory, University of Cambridge, JJ Thompson Avenue, CB3 OHE Cambridge, UK \\ *corresponding author, E-mail: Varindra@ieee.org
}

\begin{abstract}
A novel metamaterial structure has been proposed for its operation at $2.4 \mathrm{GHz}$. A circular disc patch antenna resonating at dual band frequency with $2.4 \mathrm{GHz}$ and $3.36 \mathrm{GHz}$ has been designed using full field solver CST MWS tool and the loading effect of the metamaterial has been shown. The loading of metamaterial shows a radial size reduction of $56.71 \%$ in the circular disc patch (dimensional space reduction by $81.26 \%$ ) while the effect of loading the metamaterial array and loading the metamaterial with defected ground plane show that without reducing the disc patch radius, the patch antenna can resonate at 1.00 and $1.942 \mathrm{GHz}$ respectively, these yield a lower frequency shift of $58.33 \%$ and $19.79 \%$. The designed metamaterial consists of two copper conductive concentric circular rings over a polyimide substrate. Various antenna parameters such as S11, VSWR, Bandwidth, Gain, Directivity and Radiation efficiency have been obtained for the circular disc patch antenna, circular disc patch antenna loaded with the metamaterial, circular disc patch antenna loaded with an array of metamaterial and are compared. A spice circuit has been derived for the reflection coefficient of the circular disc patch without loading the metamaterial, circular disc patch loaded with metamaterial using Keysight based ADS tool for its inclusion in a traditional electrical circuit solver tool.
\end{abstract}

\section{Introduction}

An influx of portable electronic devices has brought new challenges in the electronics component miniaturization. The antenna being the communication media across various components needs to be miniaturized to save the real estate. The PCB based microstrip antennas although are small and low profile in size, at lower frequency for its applications such as Bluetooth, WLAN, WiFi and RFID the antenna dimension is still large. Past studies have shown many miniaturization techniques such as high permittivity substrate [1-3], dielectric loading [4,5], shorting pins [6-8] and slots [9] towards antenna patch miniaturization but the side effect arising out of the miniaturization brings in some reduction in its efficiency, gain and a decrease in bandwidth $[10,11]$ apart from the impedance mismatch. An artificial metamaterial with its negative permittivity and permeability being loaded over the ground plane for the patch antenna allows it to resonate in the desired frequency range at smaller dimension without a loss in its antenna parameters. This is achieved due to the metamaterial structure itself providing resonance at the subwavelength. Previous works with the application of metamaterial by many authors [1219] have brought new research with the metamaterial being used for its gain enhancement and bandwidth improvement for a radiating patch. Although there can be variety of metamaterial shapes, a simple metamaterial structure using two concentric metal rings has been used here. The work presented here provides a design of Circular Ring Resonator (CRR) based Double Negative (DNG) metamaterial over the frequency range $1.5-4 \mathrm{GHz}$. The loading of this CRR metamaterial allows a radial size reduction from $39.32 \mathrm{~mm}$ to $17.02 \mathrm{~mm}$ (reduction of $56.71 \%$ ) in the patch element for its resonance at $2.4 \mathrm{GHz}$ while providing a similar bandwidth, gain and efficiency. In addition to the miniaturization of the radiating patch element with the metamaterial, the loading of metamaterial array over a fixed size patch element has shown a lowering in resonance frequency from $2.4 \mathrm{GHz}$ to $1.00 \mathrm{GHz}$ (reduction by $58.33 \%$ ) while the loading of metamaterial array with defected ground plane provides a lowered resonance frequency shift from $2.4 \mathrm{GHz}$ to $1.942 \mathrm{GHz}$ (reduction by $19.79 \%$ ). Since the reflection coefficient for the patch element has been obtained using full field solver tool CST MWS, an equivalent transfer function for its spice circuit has been obtained using Keysight based ADS tool (2012.08) and compared for its verification. The paper has been divided into the following Sections with Sec. 1 for the Introduction, Sec. 2 presents components of antenna with Sec. 2.1 for CRR metamaterial design, Sec. 2.2 for patch design with and without loading metamaterial while Sec. 3 talks about the planar patch and its resonance frequency shift with the loading of DNG metamaterial structure and its patch size equivalence without loading CRR metamaterial. The result has been described in Sec. 4. The Spice circuit provides a convenient mechanism to integrate electrical element into any circuit solver tool, its extraction has been also shown in Sub-sec. 2.2.1, 2.2.2 and 2.2.3.

\section{Antenna structural design}

\subsection{CRR metamaterial}

The metamaterial is a type of material which does not exist or does not fall within a class of conventional materials however is created using natural materials. A metamaterial gains its properties (' $\varepsilon$ ', ' $\mu$ ') from its structure rather than the 
material itself thus any material in a defined shape can form a metamaterial. First appearance and application of metamaterial was described by Pendry et al. [4,5], [20], Smith et al. [21,22] in the early 2000 where it was shown that metamaterial can provide a negative permittivity ' $\varepsilon$ ' and permeability ' $\mu$ '. It led towards the development of experimental verification of the LHM metamaterial. However within the last few years, the application of metamaterials has become widespread with many researchers across various disciplines [14-19]. A DNG material is known for its provision of negative refractive index and supports forward and backward energy flow at the same time with a $180^{\circ}$ phase shift in phase $\left(\mathrm{v}_{\mathrm{p}}\right)$ and group velocity $\left(\mathrm{v}_{\mathrm{g}}\right)$ [6]. Fig. 1 shows two concentric rings made of copper conductor with its thickness of $0.01 \mathrm{~mm}$ and outer radius ' $\mathrm{R}$ ' of $7.1 \mathrm{~mm}$, width ' $\mathrm{w}$ ' $0.8 \mathrm{~mm}$ and spacing ' $\mathrm{g}$ ' of 0.5 $\mathrm{mm}$ has been designed over a polyimide substrate (dielectric constant of 3.5 and tangent loss of 0.0027 ) with a dimension of $14.6 \mathrm{~mm} \times 14.6 \mathrm{~mm} \times 1.6 \mathrm{~mm}$. CST microwave studio has been used to design the model and get its simulation results. The analytical function (1-5) can be used to plot the permittivity and permeability function over the frequency range and is shown in Fig. 2.

$$
\begin{array}{r}
z=\sqrt{\frac{\left(1+S_{11}\right)^{2}-S_{21}^{2}}{\left(1-S_{11}\right)^{2}-S_{21}^{2}}} \\
e^{\left(j n k_{0} d\right)}=A \pm j \sqrt{\left(1-A^{2}\right)} \\
A=\frac{\left(1-S_{11}^{2}+S_{21}^{2}\right)}{\left(2 S_{21}\right)} \\
\varepsilon=n / z \\
\mu=n \times z
\end{array}
$$

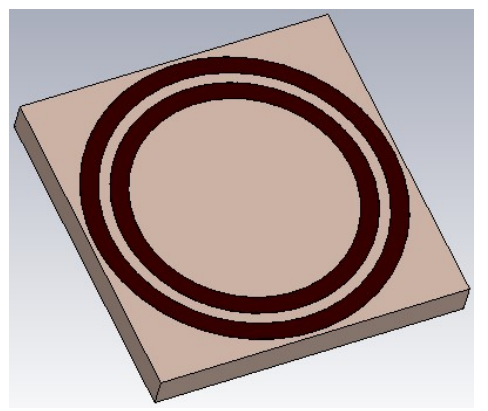

Figure 1: CRR structure.

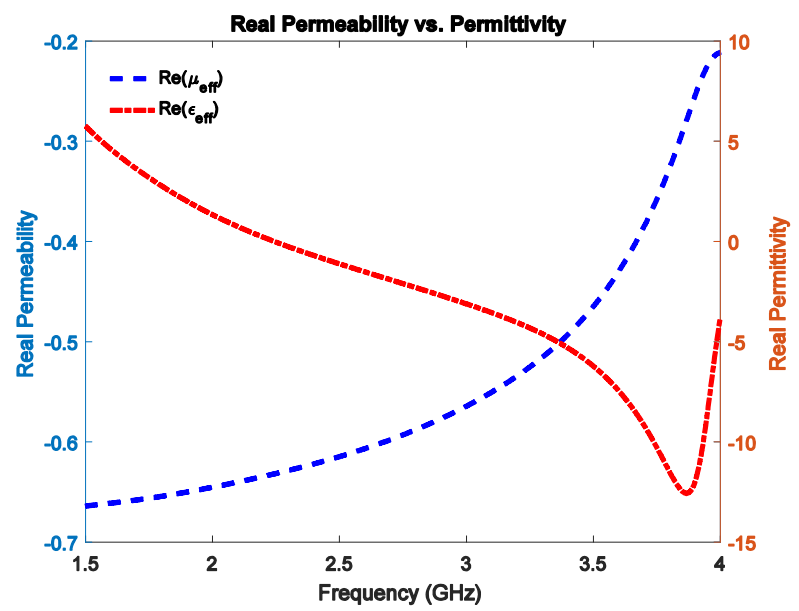

Figure 2: Real Permeability vs. Permittivity plot.

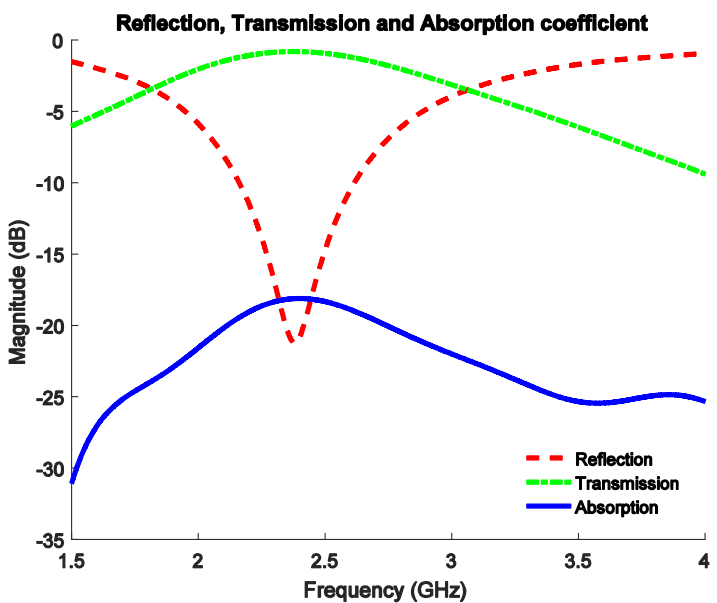

Figure 3: Reflection, Transmission and Absorption magnitude of the CRR.

The CRR structure is completely embedded within a TEM waveguide to derive the simulation result and is excited with an electric field along its $\mathrm{x}$ - direction while PEC and PMC conditions are applied along its orthogonal directions. Fig. 3 shows the plot of the return, transmission and absorption magnitude $[23,24]$ of the CRR structure.

\subsection{Planar patch}

Times Fig. 4 shows a design of circular disc patch antenna without loading CRR metamaterial with its resonance at 2.4 and $3.36 \mathrm{GHz}$ while Fig. 5 shows the bottom side of the circular disc patch with loading CRR. Similarly Fig. 6 shows the bottom side of the circular disc patch antenna when the ground is defected with loading of CRR metamaterial and resonates at $2.4 \mathrm{GHz}$. 


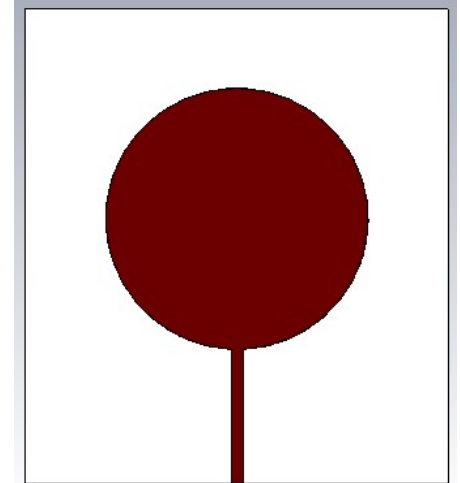

Figure 4: Patch without CRR.

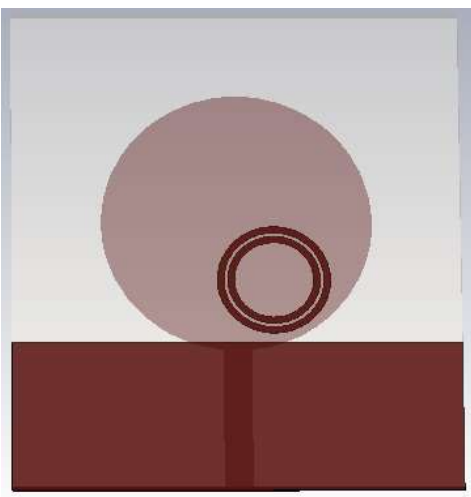

Figure 5: Patch with CRR loading.

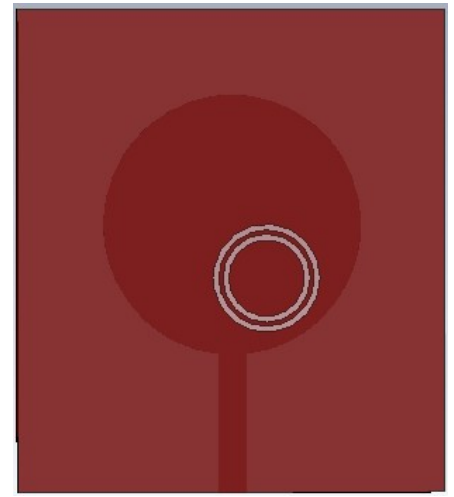

Figure 6: Patch with CRR defected ground.

The patch antenna has a circular disc element with its 39.32 $\mathrm{mm}$ radius and $0.01 \mathrm{~mm}$ copper conductive thickness and the patch is connected with a copper conductive feed of dimension $40.32 \mathrm{~mm} \times 3.6 \mathrm{~mm} \times 0.01 \mathrm{~mm}$. The patch element has been designed over $1.6 \mathrm{~mm}$ thick polyimide substrate (with its relative permittivity 3.5 and tangent loss of 0.0027 ) with its dimension of $126.64 \mathrm{~mm} \times 142.96 \mathrm{~mm}$ x $0.01 \mathrm{~mm}$ while the substrate has been laid over a copper conductive patch for its ground layer and has a dimension of $126.64 \mathrm{~mm} \times 142.96 \mathrm{~mm} \times 0.01 \mathrm{~mm}$. The circular disc patch antenna loaded with CRR metamaterial has been designed using copper conductive element with $17.02 \mathrm{~mm}$ for outer radius and thickness $0.01 \mathrm{~mm}$ while its feed has a dimension of $19.72 \mathrm{~mm} \times 3.6 \mathrm{~mm} \times 0.01 \mathrm{~mm}$. Similar to the patch antenna without CRR metamaterial, the patch element has been designed over $1.6 \mathrm{~mm}$ thick polyimide substrate (with its relative permittivity 3.5 and tangent loss of 0.0027 ) with its dimension of $50.6 \mathrm{~mm} \times 54.5 \mathrm{~mm} \times 0.01 \mathrm{~mm}$ while the substrate has been laid over a copper conductive patch for its ground layer and has a dimension of $50.6 \mathrm{~mm} \times 54.5 \mathrm{~mm} \times$ $0.01 \mathrm{~mm}$. The CRR metamaterial has been loaded at its ground layer at $(-4.7 \mathrm{~mm}, 7 \mathrm{~mm})$ from the center of the circular patch.

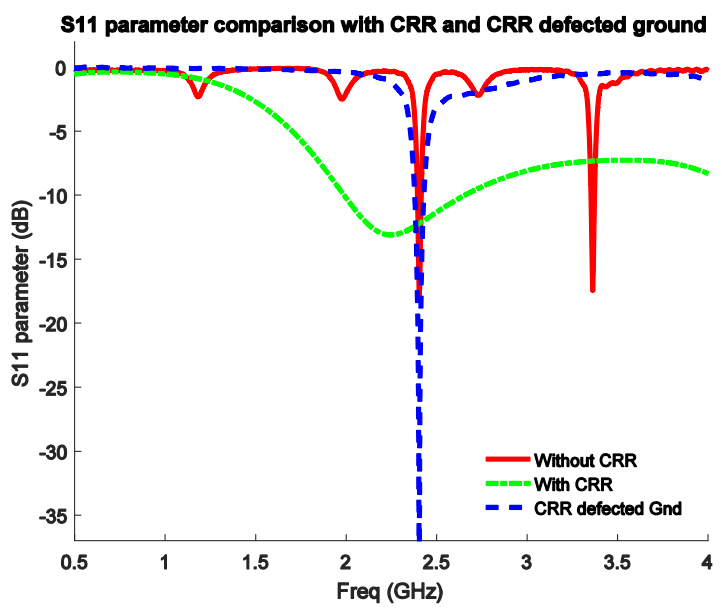

Figure 7: S11 parameter for planar patch with and without CRR loading.

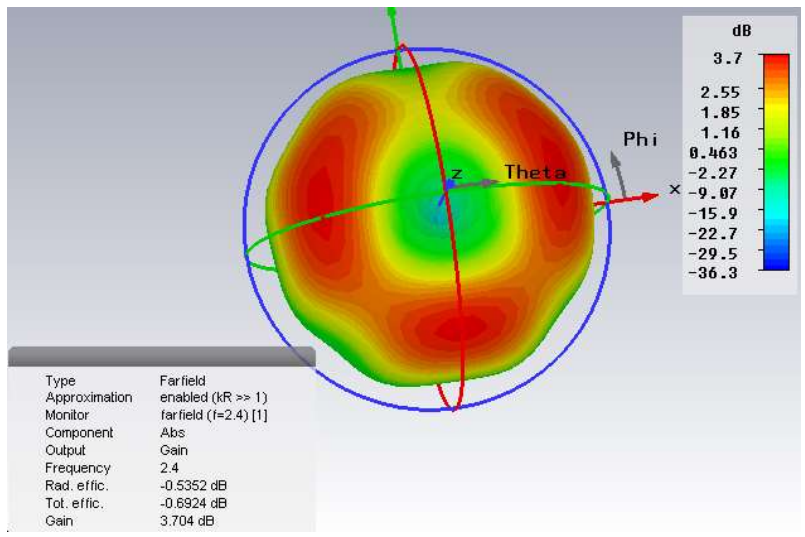

Figure 8: Radiation diagram for patch without CRR at 2.4 $\mathrm{GHz}$.

A comparison of the reflection coefficient for the patch antenna without loading CRR metamaterial and with loading CRR metamaterial has been plotted and is shown in Fig. 6. As shown in Fig. 7, the patch element loaded with CRR metamaterial resonates at 2.4 and $3.36 \mathrm{GHz}$ while providing a radial size reduction of $56.71 \%$ with the radius from 39.32 $\mathrm{mm}$ to $17.02 \mathrm{~mm}$, thus saving a dimensional space by $81.26 \%$. The S11 parameter for the patch without the metamaterial has been similar to the S11 parameter for the patch element loaded with metamaterial with the magnitude below $-10 \mathrm{~dB}$ and they provide comparable antenna parametric results. The antenna radiation for the planar patch without metamaterial while resonating at 2.4 and $3.36 \mathrm{GHz}$ is shown in Figs. 8 and 9. 


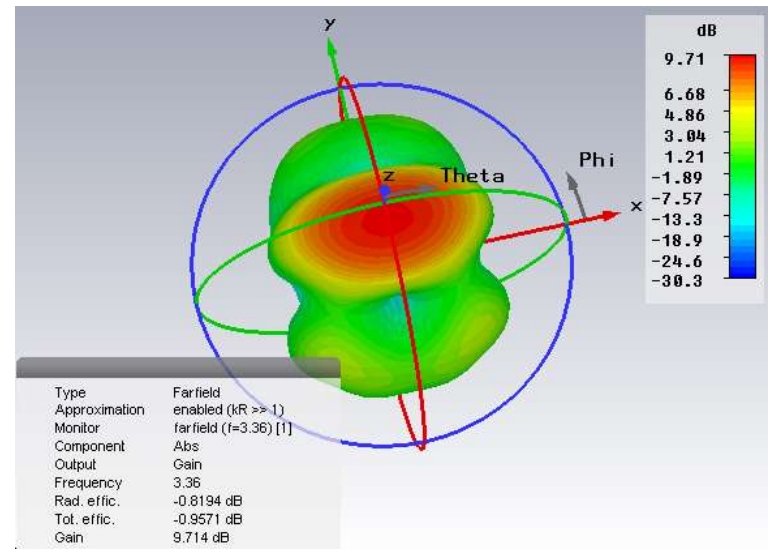

Figure 9: Radiation diagram for patch without CRR at 3.36 $\mathrm{GHz}$.

Similarly the radiation of the patch when loaded with CRR metamaterial and CRR metamaterial defected ground at its 2.4 GHz resonant frequency are shown in Figs. 10 and 11.

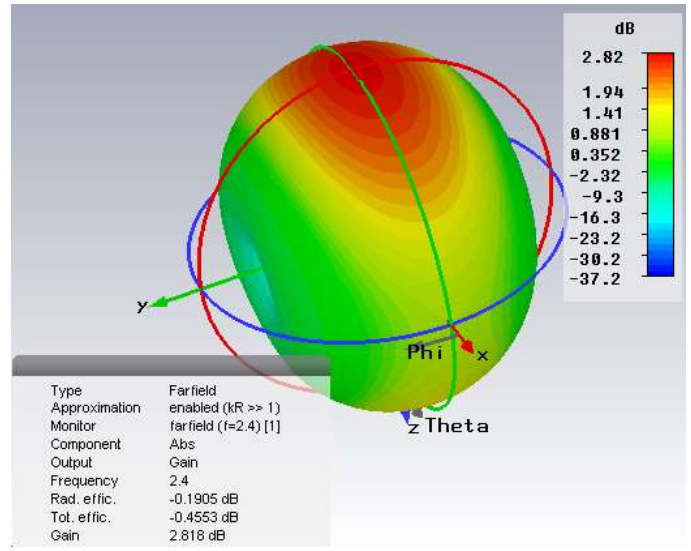

Figure 10: Radiation diagram for patch with CRR loading.

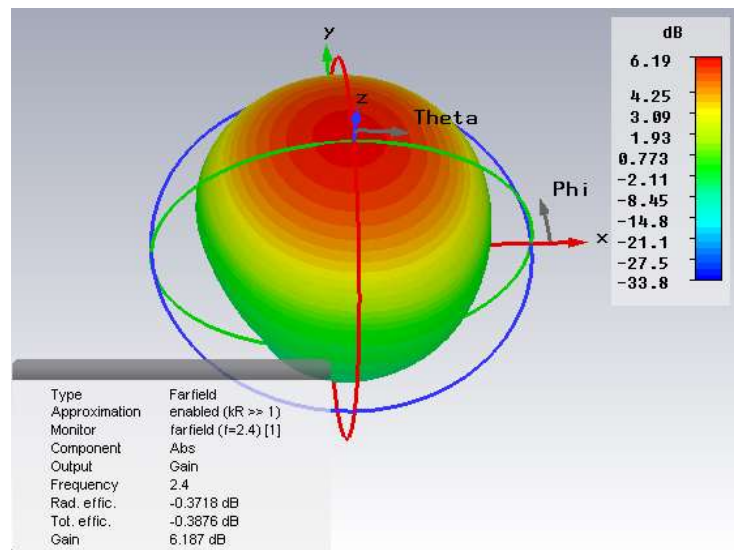

Figure 11: Radiation diagram for patch with CRR defected ground

\subsubsection{Spice circuit for patch without CRR}

As the spice circuit of the antenna can provide electrical inclusion in the traditional circuit solver tools, an equivalent spice circuit has been derived here using ADS.

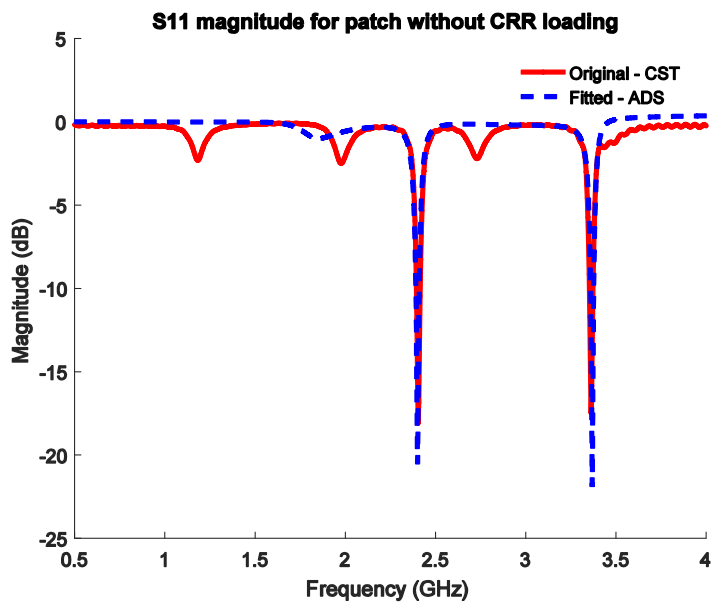

Figure 12: S1 1 original and fitted magnitude for patch without CRR.

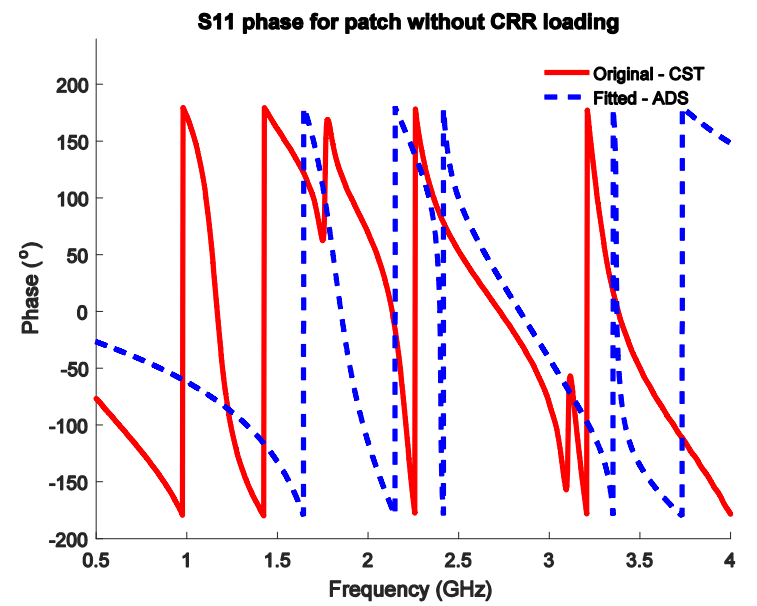

Figure 13: S11 original and fitted phase for patch without CRR.

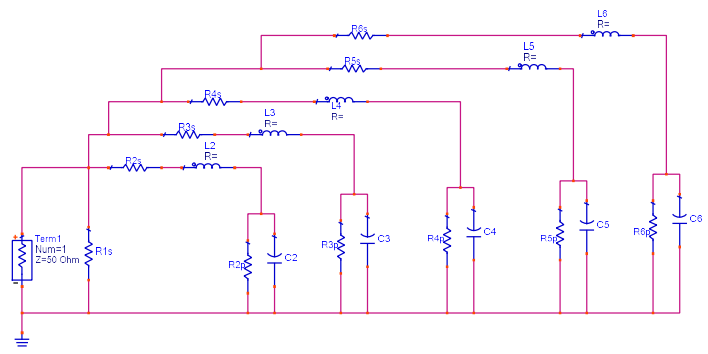

Figure 14: Spice circuit for patch antenna without CRR.

Figures 12 and 13 show the original and fitted response of the magnitude and phase for the S11 parameter. Figure 14 shows the obtained equivalent spice circuit while Table 1 provides the individual RLC parametric value. These plots show that the fitted parameters provide a similar response of a full field solver tool response. 


\subsubsection{Spice circuit for patch loaded with CRR}

Table 1: RLC parameters for the spice circuit without CRR.

\begin{tabular}{lccc}
\hline & Stage 4 & Stage 5 & Stage 6 \\
\hline $\mathrm{R}_{\mathrm{s}}(\mathrm{i})(\Omega)$ & -0.714 & 1.795 & -120.291 \\
$\mathrm{~L}(\mathrm{i})(\mathrm{nH})$ & 13.42 & 79.18 & 106.7 \\
$\mathrm{C}(\mathrm{i})(\mathrm{fF})$ & 408.7 & 28.58 & 40.24 \\
$\mathrm{R}_{\mathrm{p}}(\mathrm{i})(\mathrm{K} \Omega)$ & 19.36 & 244.036 & 19.4603 \\
& & & \\
\hline & Stage 1 & Stage 2 & Stage 3 \\
\hline $\mathrm{R}_{\mathrm{s}}(\mathrm{i})(\Omega)$ & -3034.05 & -4.90389 & 2.211 \\
$\mathrm{~L}(\mathrm{i})(\mathrm{nH})$ & & 5.065 & 16.07 \\
$\mathrm{C}(\mathrm{i})(\mathrm{fF})$ & & 358.6 & 583.338 \\
$\mathrm{R}_{\mathrm{p}}(\mathrm{i})(\mathrm{K} \Omega)$ & & 3.494 & -14.23 \\
\hline
\end{tabular}

As defined in Sec. 2.2.1, the spice circuit equivalence of the S11 parameter for the planar patch antenna loaded with CRR metamaterial has been obtained and their S1 1 magnitude and phase plots have been shown in Figs. 15 and 16. Table 2 provides the obtained RLC parameters while Fig. 17 shows the spice circuit.

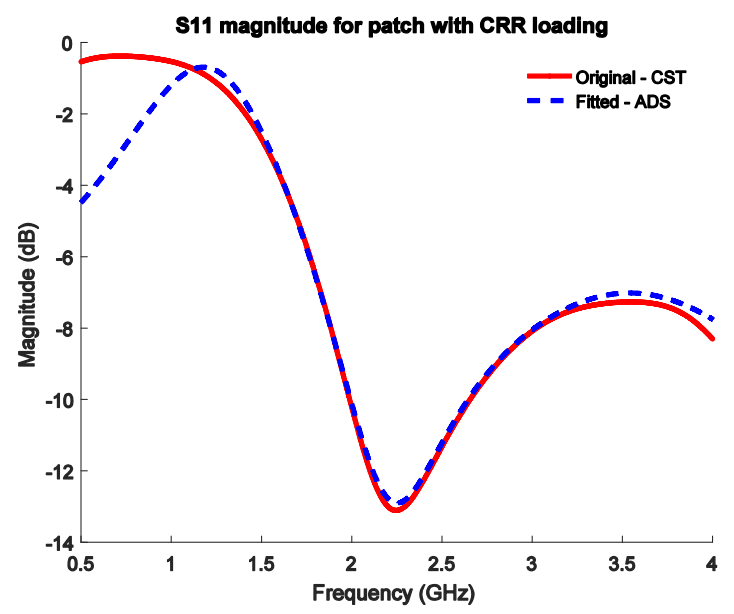

Figure 15: S11 original and fitted magnitude for patch with CRR.

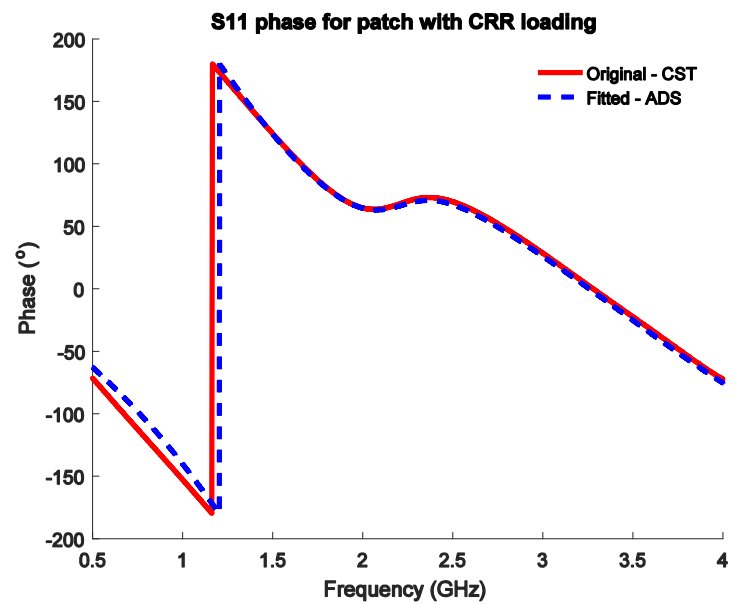

Figure 16: S11 original and fitted phase for patch with CRR.
Table 2: RLC parameters for the spice circuit with CRR.

\begin{tabular}{lcccc}
\hline & Stage 1 & Stage 2 & Stage 3 & Stage 4 \\
\hline $\mathrm{R}_{\mathrm{s}}(\mathrm{i})(\Omega)$ & 59.277 & 989.456 & 2.548 & 82.99 \\
$\mathrm{~L}(\mathrm{i})(\mathrm{pH})$ & & 9766.506 & 7175.657 & 14971.116 \\
$\mathrm{C}(\mathrm{i})(\mathrm{fF})$ & & 10.575 & 2438.607 & 317.0234 \\
$\mathrm{R}_{\mathrm{p}}(\mathrm{i})(\mathrm{K} \Omega)$ & & -1.0854 & -5.993 & 3.225
\end{tabular}

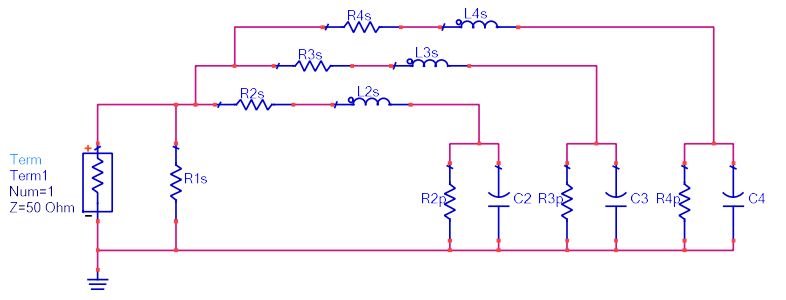

Figure 17: Spice circuit for patch antenna with CRR.

2.2.3. Spice circuit for patch loaded with CRR defected ground

An equivalent spice circuit has been derived here using ADS.

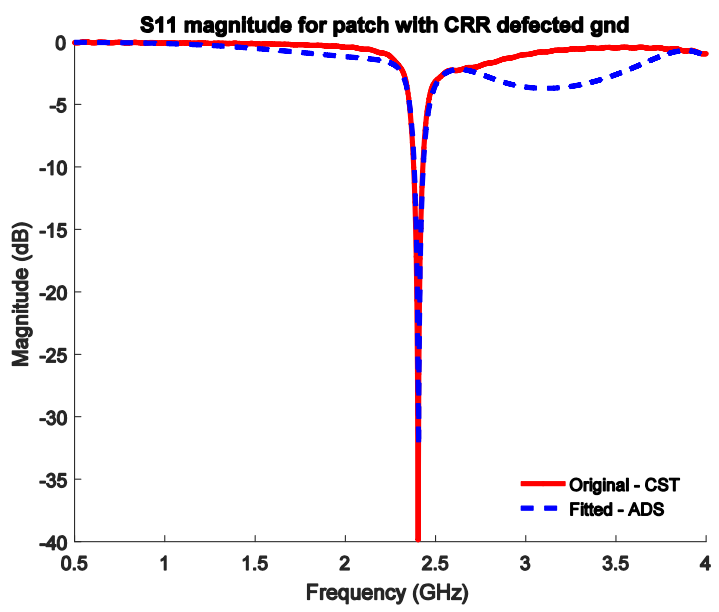

Figure 18: S1 1 original and fitted magnitude with CRR defected ground.

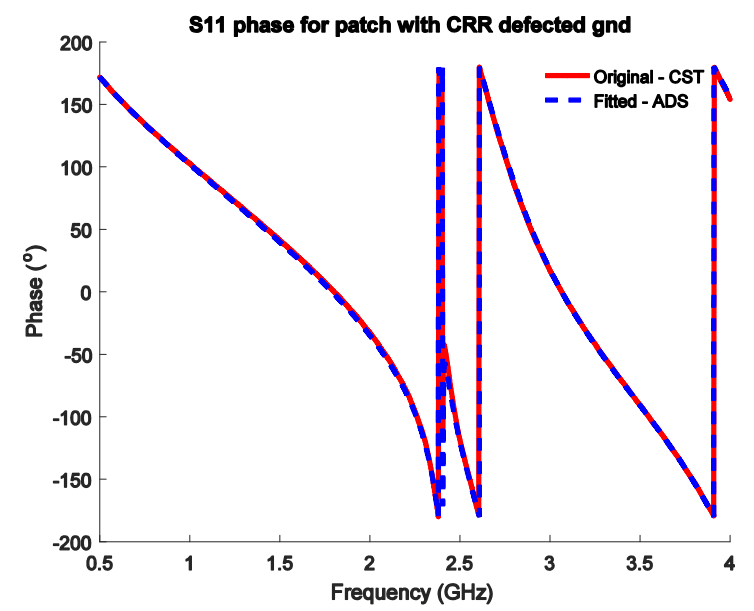

Figure 19: S1 1 original and fitted magnitude with CRR defected ground. 
Table 3: RLC parameters for the spice circuit with CRR defected ground.

\begin{tabular}{|c|c|c|c|}
\hline & Stage 1 & Stage 2 & Stage 3 \\
\hline $\mathrm{R}_{\mathrm{s}}(\mathrm{i})(\Omega)$ & 525.667 & 33.222 & 7.0448 \\
\hline L(i) $(\mathrm{nH})$ & & 1.4148 & 9.393 \\
\hline C(i) (fF) & & 448.814 & 176.352 \\
\hline$\underline{\mathrm{R}_{\mathrm{p}}(\mathrm{i})(\mathrm{K} \Omega)}$ & & -0.6085 & -10.779 \\
\hline & Stage 4 & Stage 5 & Stage 6 \\
\hline$\overline{\mathrm{R}_{\mathrm{s}}(\mathrm{i})(\Omega)}$ & 0.1051 & 1.4287 & 77.484 \\
\hline L(i) (nH) & 6.457 & 18.673 & 59.288 \\
\hline $\mathrm{C}(\mathrm{i})(\mathrm{fF})$ & 18975.487 & 199.456 & 76.0828 \\
\hline $\mathrm{R}_{\mathrm{p}}(\mathrm{i})(\mathrm{K} \Omega)$ & 33.496 & 18.393 & -13.717 \\
\hline
\end{tabular}

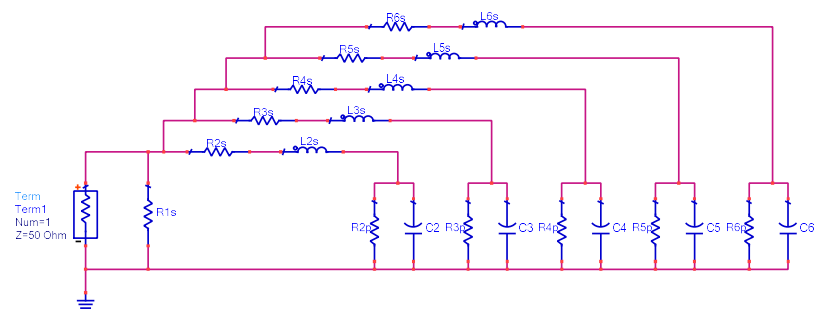

Figure 20: Spice circuit for patch antenna without CRR.

Figures 18 and 19 show the original and fitted response of the magnitude and phase for the S11 parameter. Figure 20 shows the obtained equivalent spice circuit while Table 3 provides the individual RLC parametric value. These plots show that the fitted parameters provide a similar response of a full field solver tool response.

\section{CRR array Loading}

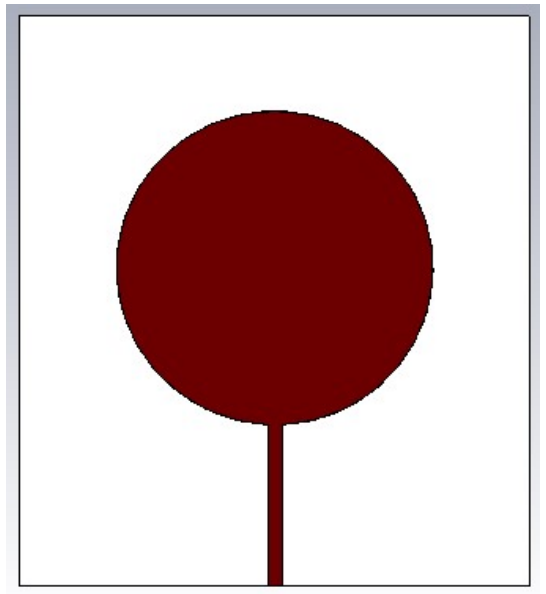

Figure 21: Patch without CRR.

The dimensional size of the patch configuration as defined in previous Sec. 2.2 has been used for the design here and is shown in Fig. 20 while the patch element loaded with an array of CRR metamaterial is shown in Fig. 21. The circular disc patch in this Section (when not loaded with CRR metamaterial and loaded with CRR metamaterial) has 39.32 $\mathrm{mm}$ radius and $0.01 \mathrm{~mm}$ copper conductive thickness, the patch is connected to copper conductive feed of dimension $40.32 \mathrm{~mm} \times 3.6 \mathrm{~mm} \times 0.01 \mathrm{~mm}$. The patch element has been designed over $1.6 \mathrm{~mm}$ thick polyimide substrate (with its relative permittivity 3.5 and tangent loss of 0.0 ) with its dimension of $126.64 \mathrm{~mm} \times 142.96 \mathrm{~mm} \times 0.01 \mathrm{~mm}$ while the substrate has been laid over a PEC conductive patch for its ground layer and has a dimension of $126.64 \mathrm{~mm} \times 142.96$ $\mathrm{mm} \times 0.01 \mathrm{~mm}$.

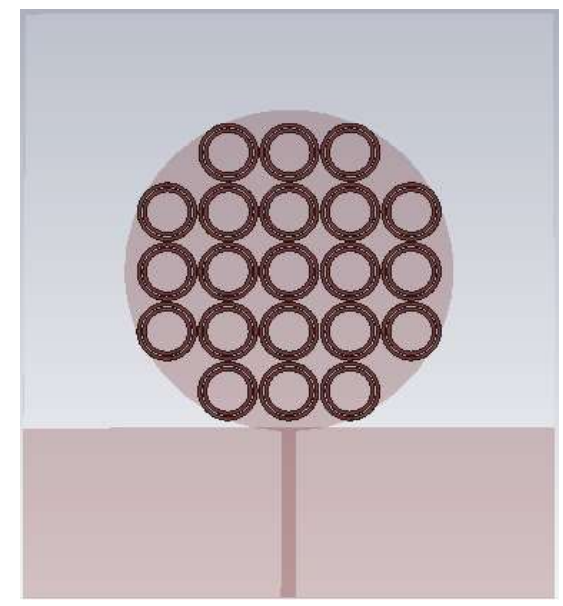

Figure 22: Patch loaded with CRR array.

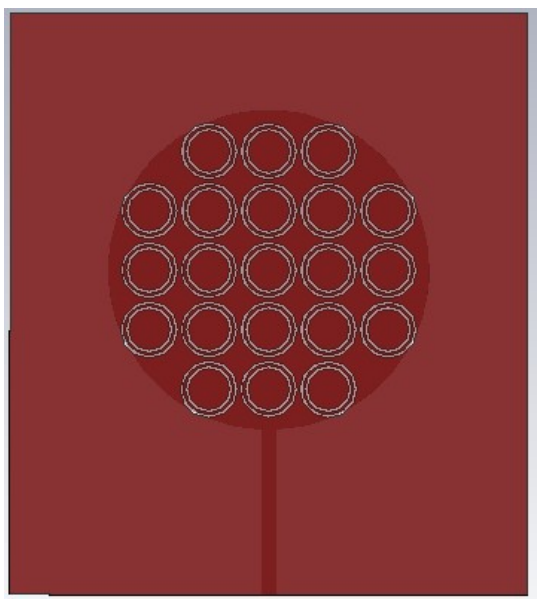

Figure 23: Patch loaded with CRR array with defected ground.

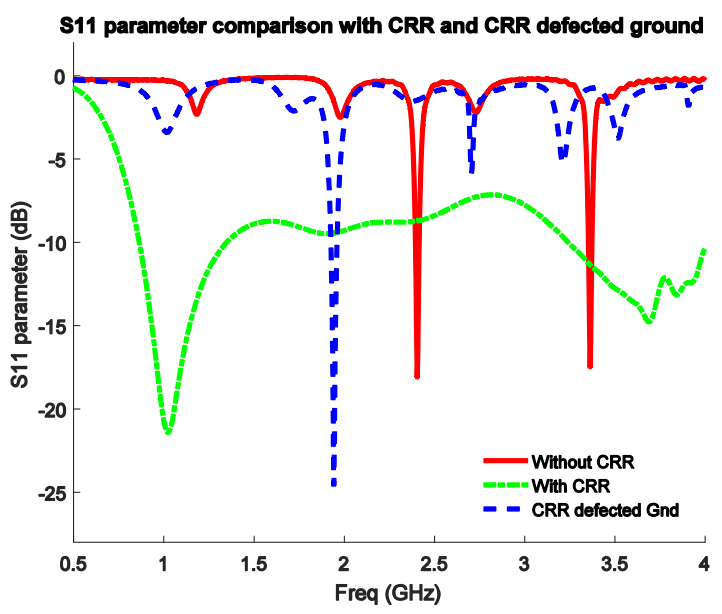

Figure 24: S11 parameter with and without CRR loading. 
Figures 22 and 23 show the patch antenna loaded with CRR metamaterial array and patch antenna with CRR metamaterial defected ground while the S11 parameter comparison has been plotted in Figure 24. With the application of loading an array of CRR metamaterial and CRR metamaterial with defected ground with $\mathrm{x}$ - and $\mathrm{y}-$ directional spacing of $14.6 \mathrm{~mm}$, the same size patch element provides a downward resonance shift while resonating at $1.00 \mathrm{GHz}$ and $1.942 \mathrm{GHz}$ respectively. Here the disc patch, feed, substrate and ground dimensions are kept the same throughout these designs.

\section{Simulation results}

Various antenna parameters such as resonance frequency, S11 parameter, bandwidth, gain, directivity and radiation efficiency when patch is not loaded with CRR metamaterial and when patch is loaded with CRR metamaterial are shown in Table 4. The patch element without loading the CRR metamaterial creates a dual band resonant structure with its resonance frequency at $2.4 \mathrm{GHz}$ and $3.36 \mathrm{GHz}$. The antenna shows a considerable gain of $3.7 \mathrm{~dB}$ and $9.71 \mathrm{~dB}$ at its resonant frequencies. The loading of CRR metamaterial structures provides an effective mechanism for the patch miniaturization, resulting in a patch size radial reduction by $64.14 \%$ with an increase in gain while providing an excellent radiation efficiency of $95.81 \%$ at $2.4 \mathrm{GHz}$ for CRR loaded patch and $91.80 \%$ at $2.4 \mathrm{GHz}$ for CRR defected ground. Similarly a comparison of antenna parameters when the patch is loaded with the CRR at its ground plane and the patch is loaded with the CRR defected ground plane has also been shown in the table. The patch antenna loaded with CRR metamaterial array shows a higher efficiency with 98.84\% while the patch element with CRR metamaterial array defected ground shows an efficiency of $93.64 \%$.

Table 4: Patch antenna (with and without CRR loading).

\begin{tabular}{|c|c|c|c|c|}
\hline Patch & $\begin{array}{c}\text { Freq }\left(\mathrm{f}_{\mathrm{o}}\right) \\
\text { in GHz }\end{array}$ & $\begin{array}{c}\text { Bandwidth } \\
(\mathrm{MHz})\end{array}$ & S11 (dB) & VSWR \\
\hline Without CRR & 2.4 & 20.7 & -18.09 & 1.28 \\
\cline { 2 - 5 } & 3.36 & 20.2 & -17.4 & 1.42 \\
\hline With CRR & 2.25 & 648.6 & -13.11 & 1.57 \\
\hline With CRR array & 1.00 & 482.57 & -20.89 & 1.20 \\
\hline $\begin{array}{c}\text { CRR defected } \\
\text { Gnd }\end{array}$ & 2.4 & 49.4 & -39.84 & 1.02 \\
\hline $\begin{array}{c}\text { CRR array } \\
\text { defected Gnd }\end{array}$ & 1.942 & 34.1 & -24.60 & 1.12 \\
\hline
\end{tabular}

\begin{tabular}{|c|c|c|c|c|}
\hline Patch & $\begin{array}{c}\text { Directivity } \\
(\mathrm{dBi})\end{array}$ & $\begin{array}{c}\text { Gain } \\
(\mathrm{dB})\end{array}$ & $\begin{array}{c}\text { Angular } \\
\text { width }\left(^{\circ}\right)\end{array}$ & $\begin{array}{c}\text { Radiation } \\
\text { Efficiency (\%) }\end{array}$ \\
\hline Without CRR & 4.24 & 3.7 & 62.9 & 88.4 \\
\cline { 2 - 5 } & 10.5 & 9.71 & 11.4 & 82.81 \\
\hline With CRR & 2.88 & 2.82 & 97.3 & 95.81 \\
\hline $\begin{array}{c}\text { With CRR } \\
\text { array }\end{array}$ & 2.52 & 2.47 & 82.3 & 98.84 \\
\hline $\begin{array}{c}\text { CRR defected } \\
\text { Gnd }\end{array}$ & 6.56 & 6.19 & 43.2 & 91.80 \\
\hline $\begin{array}{c}\text { CRR array } \\
\text { defected Gnd }\end{array}$ & 4.42 & 4.13 & 45.0 & 93.64 \\
\hline
\end{tabular}

\section{Conclusions}

This paper presents an effective miniaturization technique for a standard sized patch antenna with the loading of CRR metamaterial structure in its individual element and array form. The patch element designed over the CRR metamaterial shows that the loading of the metamaterial reduces the patch radial size by $56.71 \%$ (or its dimensional space by $81.26 \%$ ) and provides an increase in radial efficiency. Similarly the loading of CRR metamaterial array while maintaining the patch size as of the patch element (without loading it with CRR metamaterial) provides a downward resonance frequency shift with resonance at 1.00 $\mathrm{GHz}$ for CRR array loaded patch and $1.942 \mathrm{GHz}$ for CRR array defected ground plane. A mechanism to derive the spice circuit for the patch antenna with and without CRR metamaterial loading has also been obtained for its inclusion in electrical circuit.

\section{Acknowledgements}

This work was completed as part of the supervision to UROP projects at the CSIC. The author would like to acknowledge the Department of Engineering, University of Cambridge for providing the necessary support and funding.

\section{References}

[1] D. H. Schaubert, K. S. Yngvesson, Experimental study of a microstrip array on high permittivity substrate. IEEE Transactions on Antennas Propagation, 34: 92-97, 1986. DOI: $10.1109 /$ TAP.1986.1143723

[2] J. S. Kula, D. Psychoudakis, W. J. Liao, C.-c. Chen, J. L. Volakis, J. W. Halloran, Patch-antenna miniaturization using recently available ceramic substrates. IEEE Antennas and Propagation Magazine, 48: 13-20, 2006. DOI: 10.1109/MAP.2006.323335

[3] D. M. Pozar, D. H. Schaubert, Microstrip Antenna. WileyIEEE Press, 1995. ISBN: 9780470545270

[4] J. B. Pendry, A. J. Holden, D. J. Robbins, W. J. Stewart, Low-Frequency Plasmons in Thin Wire Structures. Journal of Physics Condensed Matter, 10: 4785-4809, 1998. DOI: 10.1088/0953-8984/10/22/007

[5] J. B. Pendry, A. J. Holden, D. J. Robbins, W. J. Stewart, Magnetism from Conductors and Enhanced Nonlinear Phenomena. IEEE Transactions on Microwave Theory and Techniques, 47: 2075-2084, 1999. DOI: 10.1109/22.798002

[6] V. G. Veselago, The Electrodynamics of Substances with Simultaneously Negative Values of $\varepsilon$ and $\mu$. Soviet Physics Uspekhi, 10: 1968. DOI: $10.1070 /$ PU1968v010n04ABEH003699

[7] R. Waterhouse, Small microstrip patch antenna. Electronics Letters, 31 : 604-605, 1995. DOI: 10.1049/el:19950426

[8] R. B. Waterhouse, S. D. Targonski, D. M. Kokotoff, Design and performance of small printed antennas. IEEE Transactions on Antennas and Propagation, 46: 1629-1633, 1998. DOI: $10.1109 / 8.736612$ 
[9] Y. Dong, H. Toyao, T. Itoh, Design and characterization of miniaturized patch antennas loaded with complementary split-ring resonators. IEEE Transactions on Antennas and Propagation, $\quad 60: \quad 772-785, \quad 2012$. DOI: $10.1109 /$ TAP.2011.2173120

[10] D. F. Sievenpiper, D. C. Dawson, M. M. Jacob, T. Kanar, S. Kim, J. Long, R. G. Quarfoth, Experimental validation of performance limits and design guidelines for Small antennas, IEEE Transactions on Antennas and Propagation, 60: 8-19, 2012. DOI: 10.1109/TAP.2011.2167938

[11] J. L. Volakis, C. C. Chen, K. Fujimoto, Small antennas: Miniaturization techniques and applications. Mc Graw-Hill education, 2010. ISBN: 9780071625531

[12] M. Eldson, O. Yurduseven, X. Dai, Wideband metamaterial solar cell antenna for $5 \mathrm{GHZ}$ Wi-Fi communication. Progress In Electromagnetics Research, 71: 123-131, 2005. DOI: 10.2528/PIERC16110302

[13] B.-I. Wu, W. Wang, J. Pacheco, X. Chen, T. M. Grzegorczyk, J. A. Kong, A study of using metamaterials as antenna substrate to enhance gain. Progress In Electromagnetics Research, 51: 295-328, 2017. DOI: 10.2528 /PIER04070701

[14] D. Schurig, J. J. Mock, B. J. Justice, S. A. Cummer, J. B. Pendry, A. F. Starr, D. R. Smith, Metamaterial electromagnetic cloak at microwave frequencies. Science, 314: 977-980, 2006. DOI: 10.1126/science.1133628

[15] H. S. Chen, B.-I. Wu, B. Zhang, J. A. Kong, Electromagnetic wave interactions with a metamaterial cloak. Phys. Rev. Lett., 99: 063903, 2007. DOI: $10.1103 /$ PhysRevLett.99.063903

[16] J. B. Pendry, D. Schurig, D. R. Smith, Controlling electromagnetic fields. Science, 312: 1780-1782, 2006. DOI: $10.1126 /$ science. 1125907

[17] W. S. Cai, U. K. Chettiar, A. Kildishev, Optical cloaking with metamaterials. Nature photon., 1: 224-227, 2007. DOI: $10.1038 /$ nphoton. 2007.28

[18] N. Engheta, R. W. Ziolkowski, Metamaterials, Physics and Engineering Explorations. IEEE-Wiley, New York, 2006. DOI: $10.1002 / 0471784192$

[19] C. Caloz, T. Itoh, Electromagnetic Metamaterials: Transmission Line Theory and Microwave Application. IEEE-Wiley, New Jersey, 2005. DOI: 10.1002/0471754323

[20] J. B. Pendry, Negative refraction makes a perfect lens. Phys. Rev. Lett., 85: 3966-3969, 2000. DOI: $10.1016 /$ j.physleta.2008.09.003
[21] D. R. Smith, W. J. Padilla, D. C. Vier, S. C. Nemat-Nasser, S. Schultz, Composite medium with simultaneously negative permeability and permittivity, Phys. Rev. Lett., 84: 41844187, 2000. DOI: 10.1103/PhysRevLett.84.4184

[22] D. R. Smith, N. Kroll, Negative Refractive Index in LeftHanded Materials. Physical Review Letters, 85: 2933-2936, 2000. DOI: 10.1103/PhysRevLett.85.2933

[23] B. S. Tung, B. X. Khuyen, N. V. Dung, Small-size metamaterial perfect absorber operating at low frequency. Adv. Nat. Sci: Nanosci. Nanotechnol, 5: 045008, 2014. DOI: $10.1088 / 2043-6262 / 5 / 4 / 045008$

[24] T. Alam, M. R. I. Faruque, M. T. A. Islam, Double-Negative Metamaterial-Inspired Mobile Wireless Antenna for Electromagnetic Absorption Reduction. Materials, 8: 48174828, 2015. DOI: $10.3390 / \mathrm{ma} 8084817$

[25] A. Erentok, R. W. Ziolkowski, Metamaterial-inspired efficient electrically small antennas. IEEE Transactions on Antennas and Propagation, 56: 691-707, 2008. DOI: 10.1109/TAP.2008.916949

[26] R. W. Ziolkowski, P. Jin, C. C. Lin, Metamaterial-Inspired Engineering. IEEE Proceedings of Antennas, 99: 1720-1731, 2011. DOI: $10.1109 / J P R O C .2010 .2091610$

[27] R. Garg, P. Bhartia, I. Bahl, Microstrip antenna design handbook. Artech House, Boston, MA, 2000. ISBN: 9780890065136

[28] A. Shelby, D. R. Smith, S. Schultz, Experimental Verification of a Negative Index of Refraction. Science, 292: 77-79, 2001. DOI: $10.1126 /$ science. 1058847

[29] M. Ramzan, K. Topalli, A Miniaturized Patch Antenna by Using a CSRR Loading Plane. International Journal of Antennas and Propagation, 1-9, 2015. DOI: $10.1155 / 2015 / 495629$

[30] H. Attia, L. Yousefi, M. M. Bait-Suwailam, Enhanced-gain microstrip antenna using engineered magnetic superstrates. IEEE Letters on Antennas and Wireless Propagation, 8: 1198-1201, 2009. DOI: 10.1109/LAWP.2009.2035149

[31] P. J. Castro, J. J. Barroso, J. P. L. Neto, Experimental study of transmission and reflection characteristics of a gradient array of metamaterial split-ring resonators. Journal of Microwaves, Optoelectronics and Electromagnetic Applications, 15: 380-389, 2016. DOI: 10.1590/2179$10742016 \mathrm{v} 15 \mathrm{i} 4658$ 